\title{
Optimizing Inventory and Pricing Policy for Seasonal Deteriorating Products with Preservation Technology Investment
}

\author{
Yong He and Hongfu Huang \\ Institute of Systems Engineering, School of Economics and Management, Southeast University, Nanjing 210096, China \\ Correspondence should be addressed to Yong He; heyong@126.com
}

Received 27 November 2012; Revised 2 February 2013; Accepted 8 March 2013

Academic Editor: Kung-Jeng Wang

Copyright @ 2013 Y. He and H. Huang. This is an open access article distributed under the Creative Commons Attribution License, which permits unrestricted use, distribution, and reproduction in any medium, provided the original work is properly cited.

The paper studies a kind of deteriorating seasonal product whose deterioration rate can be controlled by investing on the preservation efforts. In contrast to previous studies, the paper considers the seasonal and deteriorating properties simultaneously. A deteriorating inventory model is developed for this problem. We also provide a solution procedure to find the optimal decisions about the preservation technology investment, the market price, and the ordering frequency. Then a case study is used to illustrate the model and the solution procedure. Finally, sensitive analysis of the optimal solution with respect to major parameters is carried out.

\section{Introduction}

The research on deteriorating items has begun from 1963. A model with exponentially decaying inventory was initially proposed by Ghare [1]. In recent years, many researchers have done a lot of work on inventory problems about deteriorating products. Deterioration is defined as decay, change, or spoilage such that the items are not in a condition of being used for their original purpose [2]. Electronic goods, radioactive substances, grains, alcohol, and gasoline are examples of deteriorating products. Also, for some products, the demand may exist for just a limited time horizon. We call such products as seasonal products, for example, Christmas trees or fireworks. Now, more and more products become deteriorating and seasonal simultaneously because of the competition and technology development, such as seasonal fashion goods (clothes, sweaters, shoes, etc.), hightech electronics products (e.g., laptops, computers, mobiles, and cameras), and some seasonal food products (such as Chinese moon cake).

Hence, this will become a very difficult problem to decide the inventory if the product is both deteriorating and seasonal. In this paper, we mainly study the optimal inventory decision of the seasonal deteriorating products.
Some researchers have studied such deteriorating inventory model, but they do not consider that the deterioration rate can be controlled.

In reality, the deterioration rate can be controlled through preservation technology investment. For example, the fruit retailer can reduce the rate of product deterioration by adopting the cool supply chain. But the preservation technology investment will lead to additional cost. Hence, a key inventory problem is to find the optimal replenishment and preservation technology investment policy which maximizes the unit time profit.

This paper is the first paper to study both the preservation technology investment and pricing strategies of deteriorating seasonal products. In this paper, a model for deteriorating seasonal products is built, in which deterioration rate can be controlled by preservation technology investment. The decision variables are the market demand, the preservation technology investment parameter, and the ordering frequency. To get the optimal solution, an algorithm is designed. To foster additional managerial insights, we perform extensive sensitivity analyses and illustrate our results with a case study.

The rest of the paper is organized as follows. Section 2 is the review of the related papers. Section 3 is the notations and assumptions. Section 4 is the description of model. Section 5 
is the algorithm and numerical examples. The last section provides concluding remarks and describes future research.

\section{Literature Review}

The property of the deterioration rate is very important in the research of deteriorating inventory. In most literatures till now, it is assumed that deterioration rate is a constant [3-8] or an exogenous variable $[2,9]$. But in many practical situations, the deterioration rate can be controlled and reduced through various efforts such as procedural changes and specialized equipment acquisition. Especially for these products with high deterioration rate such as refrigerated food, fruit and vegetable, and fresh seafood, the firm has strong willingness to adopt the preservation technology to decrease the deterioration rate. Recently, some papers started to study the deteriorating inventory with preservation technology investment. Blackburn and Scudder [10] studied the optimal control of warehouse temperature under warehouse capacity constraints. They also proved that it is beneficial to share the inventory between supply chain members. Kouki et al. [11] found that when warehouse temperature can be controlled, a continuous temperature control policy can be very efficient. Musa and Sani [12] studied the model when the deterioration rate is noninstantaneous and deterioration rate can be controlled by preservation technology investment. Hsu et al. [13] proposed that the cost of preservation and the deterioration rate satisfy the equation $\lambda=k-M(\varepsilon) . M(\varepsilon)$ is the reduced deterioration rate after investing on preservation technology. The first derivative of $M(\varepsilon)$ is positive, while the second derivative is negative. Similar to Hsu et al. [13], Dye and Hsieh [14] proposed that the cost of preservation and the deterioration rate satisfy the equation $\lambda(t)=\lambda_{0}(t)(1-M(\varepsilon))$.

In addition to the deterioration rate, market demand is another very important factor considered in this paper. In some situations, the demand rate is assumed to be a constant (see [15]). But in real life, demand can hardly be a constant. It may change with time (see [16-18]), or it can be influenced by inventory level $[19,20]$ and marketing efforts [2]. At the same time, market price is highly related to demand. It is an important decision variable in many literatures. For example, in the papers of Shah et al. [2], Dye et al. [17], and Liang and Zhou [7], they also regarded price as a decision variable.

For some seasonal deteriorating products, the demand can only exist for a limited time horizon. Since the time horizon is fixed, it is necessary to decide the ordering frequency in a limited time horizon instead of the ordering period length. Some people have considered such situation, such as Sana et al. [3] and Yang et al. [21]. But they did not consider that the deterioration rate can be controlled.

\section{Notation and Assumptions}

3.1. Notation. The notation in this paper is listed below.

Decision Variables

$n$ : Ordering frequency

$\alpha$ : Cost of preservation technology investment per unit time
$p$ : Market price
$q$ : Ordering quantity.

\section{Constant Parameters}
c: Buying cost per unit
$h$ : Inventory holding cost per unit per time
$I(t)$ : Inventory level of a time point
$A$ : Ordering cost per order
$D(p)$ : Market demand, $D(p)=b-a p$
$b$ : Demand scale
a: Price sensitive parameter
TP: Total profit of the selling season.

3.2. Assumptions. The model in this paper is built on the base of the following assumptions.

(1) Market demand is linear related to market price.

(2) Market demand only exists in a limited time horizon $T$.

(3) Demand cannot be backlogged.

(4) Ordering lead time is zero.

(5) Deteriorated products have no value, and there is no cost to dispose or store them.

(6) The relationship of deterioration rate and the preservation technology investment parameter satisfies $\partial \lambda(\alpha) / \partial \alpha<0, \partial^{2} \lambda(\alpha) / \partial \alpha^{2}>0$. Hence, in this paper we assume that $\lambda(\alpha)=\lambda_{0} e^{-\delta \alpha}$. Here, $\lambda(\alpha)$ is the deterioration rate after investing on preservation technology, $\lambda_{0}$ is the deterioration rate without preservation technology investment, and $\delta$ is the sensitive parameter of investment to the deterioration rate.

(7) The cost of preservation technology investment per unit time is restricted to $\alpha \in[0, \bar{\alpha}]$.

\section{Model}

This study considers a single retailer's inventory policy in which the deterioration rate is affected by the preservation technology investment. For seasonal products, the decision variables are the market price, the ordering frequency, and the preservation technology investment parameter.

In this model, there are two tradeoffs. The first one is the tradeoff between the ordering frequency and the ordering cost per order. By increasing ordering frequency, we can decrease the deteriorating cost. But the ordering cost increases. The second tradeoff is the preservation technology investment and the deteriorating cost. By increasing the preservation technology investment, deteriorating cost decreases.

According to the assumption, the time length is equal in all the ordering periods. So, we only study the first period. In the first period, according to the modeling of exponential 


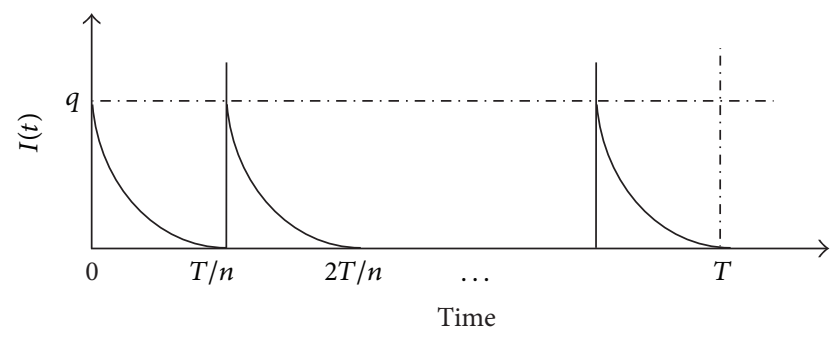

FIgURE 1: The inventory system.

deteriorating inventory in Ghare [1], the inventory level $I(t)$ can be depicted as Figure 1 and formulated as

$$
\frac{\partial I(t)}{\partial t}=-\lambda(\alpha) I(t)-D(p) \quad\left(t \in\left[0, \frac{T}{n}\right]\right) .
$$

The boundary condition is

$$
I\left(\frac{T}{n}\right)=0 .
$$

By solving (1), we have

$$
I(t)=\frac{D(p)}{\lambda(\alpha)}\left(e^{\lambda(\alpha)(T / n-t)}-1\right) .
$$

The total profit of the season can be formulated as

$\mathrm{TP}=$ Sales revenue - Buying cost - Ordering cost

$$
\text { - Inventory cost - Preservation cost. }
$$

(1) Sales revenue: The total revenue in time $T$ can be formulated as

$$
R=p \cdot D(p) \cdot T
$$

(2) Buying cost: According to (3), we can know the ordering quantity. The total buying cost can be formulated as

$$
C_{p}=n \cdot c \cdot q=n \cdot c \cdot \frac{D(p)}{\lambda(\alpha)}\left(e^{\lambda(\alpha) T / n}-1\right) .
$$

(3) Inventory cost: The total inventory quantity

$$
\begin{aligned}
\text { Inv } & =n \cdot D(p) \cdot \int_{0}^{T / n} I(t) d t \\
& =n \cdot \frac{D(p)\left(e^{\lambda(\alpha)(T / n)}-\lambda(\alpha)(T / n)-1\right)}{\lambda^{2}(\alpha)} .
\end{aligned}
$$

The formulation of the total inventory cost is

$$
C_{h}=h \cdot \text { Inv. }
$$

(4) Ordering cost: Ordering cost is a constant in every period. The total cost can be formulated as

$$
C_{o}=n \cdot A \text {. }
$$

(5) Preservation cost:

$$
I_{0}=\alpha T \text {. }
$$

Hence, the profit function is

$$
\begin{aligned}
\operatorname{TP}(n, \alpha, p)= & p \cdot D(p) \cdot T-n \cdot c \cdot q \\
& -h \cdot \operatorname{Inv}-n \cdot A-I_{0} .
\end{aligned}
$$

The problem is to solve the next program

$$
\begin{array}{ll}
\min & \operatorname{TP}(n, \alpha, p) \\
\text { s.t. } & D(p)>0 \\
& p>0 \\
& 0 \leq \alpha \leq \bar{\alpha} .
\end{array}
$$

According to the Taylor series theory, for small $\lambda$ and $T / n$ values, the exponential function can have an approximation of $e^{\lambda T / n} \approx 1+\lambda T / n+(\lambda T / n)^{2} / 2$. This assumption is very common in many other papers, such as Lo et al. [22] and Wee et al. [23]. Substituting the equation into the target function, we have

$$
\begin{aligned}
\operatorname{TP}(n, \alpha, p)= & p D(p) T-c D(p)\left(T+\frac{T^{2}}{2 n} \lambda(\alpha)\right) \\
& -h D(p) \cdot \frac{T^{2}}{2 n}-\alpha T-n A .
\end{aligned}
$$

Proposition 1. When market price $p$ and preservation cost $\alpha$ are fixed, the profit function $\operatorname{TP}(n, \alpha, p)$ is concave in ordering frequency $n$.

Proof. The first and second partial derivatives of the target function $\operatorname{TP}(n, \alpha, p)$ with respect to $n$ are as follows:

$$
\begin{gathered}
\frac{\partial \operatorname{TP}(n, \alpha, p)}{\partial n} \\
=\frac{\left(c D(p) \lambda(\alpha) T^{2} / 2+h D(p) T^{2} / 2\right)}{n^{2}}-A, \\
\frac{\partial^{2} \operatorname{TP}(n, \alpha, p)}{\partial n^{2}}=-\frac{\left(c D(p) \lambda(\alpha) T^{2}+h D(p) T^{2}\right)}{n^{3}}<0 .
\end{gathered}
$$

According to (15), we can know that the profit function is concave in $n$. The ordering frequency is an integer. So, the search for the optimal ordering frequency is reduced to find a local optimal solution.

Proposition 2. For known $n$ and fixed $p$, we have the following.

(1) If $\Delta_{1}(n, p) \leq 0, \operatorname{TP}(n, \alpha, p)$ has a maximum value at $\alpha^{*}=0$.

(2) If $\Delta_{2}(n, p) \geq 0, T P(n, \alpha, p)$ has a maximum value at $\alpha^{*}=\bar{\alpha}$. 
(3) If $\Delta_{1}(n, p)>0$ and $\Delta_{2}(n, p)<0, T P(n, \alpha, p)$ is concave and reaches its global maximum at point $\alpha^{*} \in$ $(0, \bar{\alpha})$ to $\operatorname{set} \partial \mathrm{TP}(n, \alpha, p) / \partial \alpha=0$.

$\left(\Delta_{1}(n, p)\right.$ and $\Delta_{2}(n, p)$ are defined in the following proof.)

Proof. The first and second partial derivatives of the target function $\operatorname{TP}(n, \alpha, p)$ with respect to $\alpha$ give

$$
\begin{gathered}
\frac{\partial \mathrm{TP}(n, \alpha, p)}{\partial \alpha}=\frac{c D(p) T^{2} \delta \lambda(\alpha)}{2 n}-T, \\
\frac{\partial^{2} \mathrm{TP}(n, \alpha, p)}{\partial \alpha^{2}}=-\frac{c D(p) T^{2} \delta^{2} \lambda(\alpha)}{2 n}<0 .
\end{gathered}
$$

For simplicity, we set $G(\alpha)=c D(p) T^{2} \delta \lambda(\alpha) / 2 n-T$.

We define $\Delta_{1}(n, p)=\left.G(\alpha)\right|_{\alpha=0}=c D(p) T^{2} \delta \lambda_{0} / 2 n-T$, $\Delta_{2}(n, p)=\left.G(\alpha)\right|_{\alpha=\bar{\alpha}}=c D(p) T^{2} \delta \lambda(\bar{\alpha}) / 2 n-T$.

It is obvious that $G^{\prime}(\alpha)<0$. So, $G(\alpha)$ is strictly decreasing in $\alpha$.

(1) If $\Delta_{1}(n, p) \leq 0, G(\alpha) \leq 0$, and $\forall \alpha \in[0, \bar{\alpha}]$, $\operatorname{TP}(n, \alpha, \mathrm{p})$ is decreasing in $\alpha \in[0, \bar{\alpha}]$. So, the optimal preservation cost is $\alpha^{*}=0$.

(2) If $\Delta_{2}(n, p) \geq 0, G(\alpha) \geq 0$, and $\forall \alpha \in[0, \bar{\alpha}]$, $\operatorname{TP}(n, \alpha, p)$ is increasing in $\alpha \in[0, \bar{\alpha}]$. So, the optimal preservation cost is $\alpha^{*}=\bar{\alpha}$.

(3) If $\Delta_{1}(n, p)>0$ and $\Delta_{2}(n, p)<0$, according to the intermediate value theorem, there exists unique value $\alpha^{*} \in(0, \bar{\alpha})$ to satisfy $G\left(\alpha^{*}\right)=0$, that is,

$$
\frac{c D(p) T^{2} \delta \lambda\left(\alpha^{*}\right)}{2 n}-T=0 .
$$

Proposition 3 indicates that when the initial deterioration rate is sufficiently small or the efficiency of the invested capital is low, there is no need to invest in preservation technology, for it is unbeneficial. Besides, if there is a constraint of the investment capital, there may be a potential for the firm to get more profit. Conclusions are proved in the case study.

Proposition 3. There exists unique $p^{*}$ which maximizes profit function $\operatorname{TP}(n, \alpha, p)$ for fixed $n$ and $\alpha$.

Proof. The first and second partial derivatives of the target function $\operatorname{TP}(n, \alpha, p)$ with respect to $n$ are as follows:

$$
\begin{aligned}
\frac{\partial \mathrm{TP}(n, \alpha, p)}{\partial p}= & (b-2 a p) T+a c\left[T+\frac{T^{2} \lambda\left(\alpha^{*}\right)}{2 n}\right] \\
& +a h \frac{T^{2}}{2 n} .
\end{aligned}
$$

Let $\partial \mathrm{TP}(n, \alpha, p) / \partial p$ be zero and solve for the optimal $p^{*}$, we have

$$
p^{*}=\frac{b}{2 a}+\frac{c}{2}\left[1+\frac{T \lambda(\alpha)}{2 n}\right]+\frac{h T}{4 n} .
$$

At point $p=p^{*}$, we have $\partial^{2} \mathrm{TP}(n, \alpha, p) /\left.\partial p^{2}\right|_{p=p^{*}}=$ $-2 a T<0$.

Thus, $p^{*}$ is the global optimal which maximizes the profit function $\operatorname{TP}(n, \alpha, p)$ for fixed $n$ and $\alpha$.

Combining Propositions 1, 2, and 3, we have Proposition 4.

Proposition 4. For fixed $n$, the optimal solution $\left(\alpha^{*}, p^{*}\right)$ that maximizes profit function $\operatorname{TP}(n, \alpha, p)$ exists and is unique. The optimal solution can be obtained through some interaction algorithms.

In the subsection, we use an interaction algorithm to solve numerical examples.

\section{Algorithm}

Step 1. Set $n=1$.

Step 2. Set $k=1$ and initialize the value of $p^{k}=p_{0}$.

Step 3. Calculate $\Delta_{1}(n, p), \Delta_{2}(n, p)$ and execute any one of the following three cases 1,2 , or 3 .

(1) If $\Delta_{1}(n, p) \leq 0$, then $\alpha_{1}^{k}=0$. Obtain $p_{1}^{k}$ from (20).

(2) If $\Delta_{2}(n, p) \geq 0$, then $\alpha_{1}^{k}=\bar{\alpha}$. Obtain $p_{1}^{k}$ from (20).

(3) If $\Delta_{1}(n, p)>0$ and $\Delta_{2}(n, p)<0$, obtain the value of $\alpha_{1}^{k}$ by solving (18). Substitute the value of $\alpha_{1}^{k}$ into (20) and to obtain the corresponding value of $p_{1}^{k}$.

Set $p^{k+1}=p_{1}^{k}$ and $\alpha^{k}=\alpha_{1}^{k}$.

Step 4. If $\left|p^{k+1}-p^{k}\right| \leq 10^{-4}$, then $\left(\alpha^{*}, p^{*}\right)=\left(\alpha^{k}, p^{k+1}\right)$ and go to Step 5. Otherwise, set $k=k+1$ and go to Step 3 .

Step 5. Calculate $\operatorname{TP}\left(n, \alpha^{*}, p^{*}\right)$. It is the maximum of profit function for fixed $n$.

Step 6. Set $n^{\prime}=n+1$, repeat Step 2 to 5 and find $\operatorname{TP}\left(n^{\prime}, \alpha^{*}, p^{*}\right)$. Go to Step 7 .

Step 7. If $\operatorname{TP}\left(n^{\prime}, \alpha^{*}, p^{*}\right) \geq \operatorname{TP}\left(n, \alpha^{*}, p^{*}\right)$, set $n=n^{\prime}$. Go to Step 6. Otherwise go to Step 8.

Step 8. Set $\left(n^{*}, \alpha^{*}, p^{*}\right)=\left(n, \alpha^{*}, p^{*}\right)$, then $\left(n^{*}, \alpha^{*}, p^{*}\right)$ is the optimal solution.

Step 9. Calculate corresponding $Q$ according to (3).

\section{Case Study}

To better illustrate our conclusions, we proposed four cases. The first one is a normal case, which is a benchmark for the other two. In the second case, there is a constraint for the investment capital. In the third and fourth case, the value of initial deterioration rate and the efficiency parameter is relatively small. Here, we apply the above algorithm to solve the problem. 
TABLE 1: Initial values of the parameters.

\begin{tabular}{ccccccccc}
\hline$A$ & $b$ & $a$ & $c$ & $h$ & $\lambda_{0}$ & $\bar{\alpha}$ & $T$ & $\delta$ \\
\hline 500 & 10 & 0.2 & 10 & 1 & 0.02 & 10 & 100 & 0.5 \\
\hline
\end{tabular}

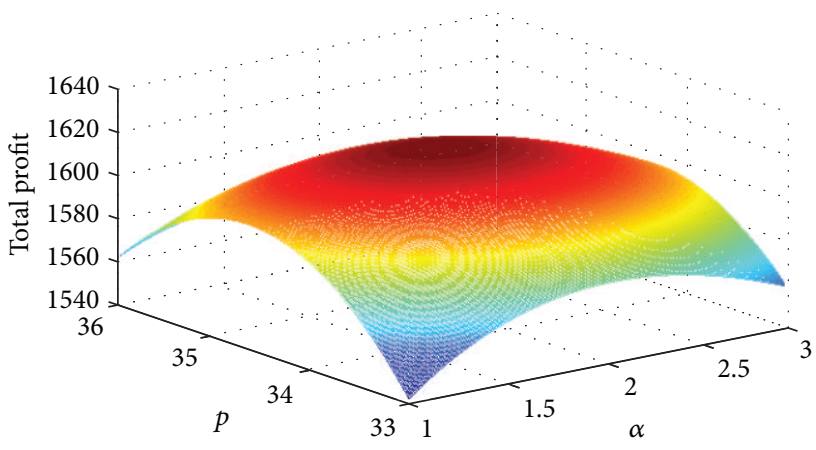

FIGURE 2: The function with respect to $p$ and $\alpha$ for fixed $n=6$.

Example 1. The initial values of the parameters are listed in Table 1.

By calculating with Matlab 7.1, when $n=6$, we can plot the relation of total profit to market price and preservation cost as Figure 2. From Figure 2, we can see that the profit function is jointly concave in market price and preservation cost. For different $n$, the optimal profit always exists. As is shown in Table 2, the profit function is concave in ordering frequency. And when $n=6$, the profit function reaches its maximum. So, the maximum of profit is $\mathrm{TP}=\$ 1621.9$.

In this example, the upper bound of investment on preservation cost is sufficiently large. The optimal solution is not on the boundary.

Example 2. In this example, we set $\bar{\alpha}=1.7500$ without change of other parameters of Example 1. From Table 3, we can see that the optimal solution is $\alpha^{*}=1.7500$ which is on the boundary and the profit is smaller than that of the first example. In practice, the maximum capital on preservation technology investment can have significant influence on the benefit of retailer.

Example 3. The initial values of the parameters are shown in Table 4. When the initial value of the deterioration rate is relatively low, that is, $\lambda_{0}=0.001$ in Table 4 , according to the algorithm, $\Delta_{1}(n, p)<0$, the optimal investment capital is $\alpha^{*}=0$. This indicates that invest in preservation technology is not beneficial when the initial value of the deterioration rate is low.

Example 4. The initial values of the parameters are shown in Table 5. When the sensitive parameter $\delta=0.01$, according to algorithm, $\Delta_{1}(n, p)<0$, so the optimal solution for the investment is $\alpha^{*}=0$. This also indicates that when the efficiency of the parameter is low, it is not beneficial to invest in preservation technology.
TABLE 2: The search process of the problem.

\begin{tabular}{cccccc}
\hline$n$ & $\alpha$ & $p$ & $\lambda$ & $q$ & $\mathrm{TP}$ \\
\hline 3 & 2.6383 & 38.78 & 0.0053 & 81.47 & 754.4 \\
4 & 2.4144 & 36.62 & 0.0060 & 71.88 & 1337.0 \\
5 & 2.1512 & 35.34 & 0.0068 & 62.64 & 1582.6 \\
$\mathbf{6}$ & $\mathbf{1 . 8 9 9 6}$ & $\mathbf{3 4 . 4 9}$ & $\mathbf{0 . 0 0 7 7}$ & $\mathbf{5 5 . 0 4}$ & $\mathbf{1 6 2 1 . 9}$ \\
7 & 1.6681 & 33.88 & 0.0087 & 48.91 & 1529.2 \\
8 & 1.4567 & 33.43 & 0.0097 & 43.93 & 1347.8 \\
9 & 1.2634 & 33.07 & 0.0106 & 39.84 & 1104.0 \\
\hline
\end{tabular}

TABLE 3: The search process of the problem.

\begin{tabular}{cccccc}
\hline$n$ & $\alpha$ & $p$ & $\lambda$ & $q$ & TP \\
\hline 3 & 1.7500 & 39.03 & 0.0083 & 83.31 & 707.65 \\
4 & 1.7500 & 36.78 & 0.0083 & 73.04 & 1300.1 \\
5 & 1.7500 & 35.42 & 0.0083 & 63.20 & 1553.4 \\
$\mathbf{6}$ & $\mathbf{1 . 7 5 0 0}$ & $\mathbf{3 4 . 5 1}$ & $\mathbf{0 . 0 0 8 3}$ & $\mathbf{5 5 . 2 1}$ & $\mathbf{1 5 9 6 . 3}$ \\
7 & 1.6681 & 33.88 & 0.0087 & 48.91 & 1529.2 \\
8 & 1.4567 & 33.43 & 0.0097 & 43.93 & 1347.8 \\
9 & 1.2634 & 33.07 & 0.0106 & 39.84 & 1104.0 \\
\hline
\end{tabular}

TABLE 4: Initial values of the parameters for Example 3.

\begin{tabular}{lcccccccc}
\hline$A$ & $b$ & $a$ & $c$ & $h$ & $\lambda_{0}$ & $\bar{\alpha}$ & $T$ & $\delta$ \\
\hline 500 & 10 & 0.2 & 10 & 1 & 0.001 & 10 & 100 & 0.5
\end{tabular}

TABLE 5: Initial values of the parameters for Example 4.

\begin{tabular}{lcccccccc}
\hline$A$ & $b$ & $a$ & $c$ & $h$ & $\lambda_{0}$ & $\bar{\alpha}$ & $T$ & $\delta$ \\
\hline 500 & 10 & 0.2 & 10 & 1 & 0.02 & 10 & 100 & 0.01
\end{tabular}

\section{Sensitive Analysis}

In this part, we performed the sensitivity analysis on the optimal solution of the model with respect to parameters $\left(A, \lambda_{0}, c, h, \delta\right)$ by changing each of the parameters by $-50 \%$, $-40 \%,-30 \%,-20 \%,-10 \%, 10 \%, 20 \%, 30 \%, 40 \%$, and $50 \%$, taking one parameter at a time and keeping the remaining parameters unchanged. Table 6 is the sensitive analysis results with respect to Example 1. Figure 3 is the percent changes of parameter on total profit for Example 1.

From Table 6, we can conclude the following.

(1) The retailer's ordering frequency is insensitive to the change of $\lambda_{0}$ and $\delta$. While, the retailer's ordering frequency is decreasing in $A$ and $c$, it is increasing in $h$. It means that when the ordering cost is high, retailer will order less frequently to reduce the cost. When buying cost is high, the increasing ordering frequency leads to a lower deterioration cost, which is beneficial for the retailer. But when the inventory holding cost rate is low, the less ordering frequency is much beneficial for the retailer.

(2) The retailer's total ordering quantity $n \cdot q$ and profit TP are both decreasing in $A$ and $c$, and insensitive on the change of $\lambda_{0}$. While the retailer's total ordering 
TABLE 6: Sensitive analysis results for Example $1(\bar{\alpha}=5.0000)$.

\begin{tabular}{|c|c|c|c|c|c|c|c|c|c|c|c|c|}
\hline & & $-50 \%$ & $-40 \%$ & $-30 \%$ & $-20 \%$ & $-10 \%$ & 0 & $+10 \%$ & $+20 \%$ & $+30 \%$ & $+40 \%$ & $+50 \%$ \\
\hline \multirow{5}{*}{$A$} & $n$ & 9 & 8 & 7 & 7 & 6 & 6 & 5 & 5 & 5 & 5 & 4 \\
\hline & $\alpha$ & 1.2634 & 1.4567 & 1.6681 & 1.6681 & 1.8996 & 1.8996 & 2.1512 & 2.1512 & 2.1512 & 2.1512 & 2.4144 \\
\hline & $p$ & 33.07 & 33.43 & 33.88 & 33.88 & 34.49 & 34.49 & 35.34 & 35.34 & 35.34 & 35.34 & 36.62 \\
\hline & $n \cdot q$ & 358.56 & 351.44 & 342.37 & 342.37 & 330.24 & 330.24 & 313.20 & 313.20 & 313.20 & 313.20 & 287.52 \\
\hline & $\mathrm{TP}$ & 3354.0 & 2947.8 & 2579.2 & 2229.2 & 1921.9 & 1621.9 & 1332.6 & 1082.6 & 832.6 & 582.6 & 337.0 \\
\hline \multirow{5}{*}{$\lambda_{0}$} & $n$ & 6 & 6 & 6 & 6 & 6 & 6 & 6 & 6 & 6 & 6 & 6 \\
\hline & $\alpha$ & 0.5133 & 0.8779 & 1.1862 & 1.4533 & 1.6889 & 1.8996 & 2.0902 & 2.2642 & 2.4243 & 2.5725 & 2.7105 \\
\hline & $p$ & 34.49 & 34.49 & 34.49 & 34.49 & 34.49 & 34.49 & 34.49 & 34.49 & 34.49 & 34.49 & 34.49 \\
\hline & $n \cdot q$ & 330.24 & 330.24 & 330.24 & 330.24 & 330.24 & 330.24 & 330.24 & 330.24 & 330.24 & 330.24 & 330.24 \\
\hline & $\mathrm{TP}$ & 1760.5 & 1724.0 & 1693.2 & 1666.5 & 1642.9 & 1621.9 & 1602.8 & 1585.4 & 1569.4 & 1554.6 & 1540.8 \\
\hline \multirow{5}{*}{$c$} & $n$ & 6 & 6 & 6 & 6 & 6 & 6 & 6 & 6 & 5 & 5 & 5 \\
\hline & $\alpha$ & 0.8172 & 1.1247 & 1.3743 & 1.5806 & 1.7536 & 1.8996 & 2.0232 & 2.1278 & 2.4540 & 2.5220 & 2.5762 \\
\hline & $p$ & 31.94 & 32.45 & 32.96 & 33.47 & 33.98 & 34.49 & 35.00 & 35.51 & 36.88 & 37.40 & 37.91 \\
\hline & $n \cdot q$ & 401.10 & 384.30 & 369.36 & 355.62 & 342.66 & 330.24 & 318.18 & 306.42 & 277.75 & 266.35 & 255.05 \\
\hline & $\mathrm{TP}$ & 3439.0 & 3046.5 & 2669.7 & 2307.3 & 1958.2 & 1621.9 & 1297.7 & 985.4 & 696.7 & 424.6 & 164.0 \\
\hline \multirow{5}{*}{$h$} & $n$ & 4 & 5 & 5 & 5 & 6 & 6 & 6 & 6 & 6 & 7 & 7 \\
\hline & $\alpha$ & 2.8430 & 2.4120 & 2.3501 & 2.2860 & 1.9537 & 1.8996 & 1.8439 & 1.7866 & 1.7275 & 1.4783 & 1.4277 \\
\hline & $p$ & 33.43 & 33.30 & 33.81 & 34.32 & 34.06 & 34.49 & 34.91 & 35.34 & 35.77 & 35.34 & 35.71 \\
\hline & $n \cdot q$ & 351.48 & 354.00 & 343.80 & 333.60 & 338.70 & 330.24 & 321.72 & 313.20 & 304.62 & 313.18 & 305.83 \\
\hline & $\mathrm{TP}$ & 3209.2 & 2837.0 & 2508.1 & 2189.4 & 1883.9 & 1621.9 & 1366.9 & 1119.0 & 878.26 & 649.85 & 443.05 \\
\hline \multirow{5}{*}{$\delta$} & $n$ & 6 & 6 & 6 & 6 & 6 & 6 & 6 & 6 & 6 & 6 & 6 \\
\hline & $\alpha$ & 0.9388 & 1.4150 & 1.6682 & 1.8032 & 1.8712 & 1.8996 & 1.9036 & 1.8927 & 1.8723 & 1.8461 & 1.8163 \\
\hline & $p$ & 34.83 & 34.71 & 34.63 & 34.57 & 34.53 & 34.49 & 34.46 & 34.43 & 34.41 & 34.40 & 34.38 \\
\hline & $n \cdot q$ & 343.50 & 339.12 & 335.94 & 333.54 & 331.68 & 330.24 & 328.98 & 327.96 & 327.12 & 326.40 & 325.74 \\
\hline & $\mathrm{TP}$ & 1511.3 & 1533.1 & 1557.0 & 1580.3 & 1602.0 & 1621.9 & 1640.0 & 1656.5 & 1671.6 & 1685.4 & 1699.8 \\
\hline
\end{tabular}

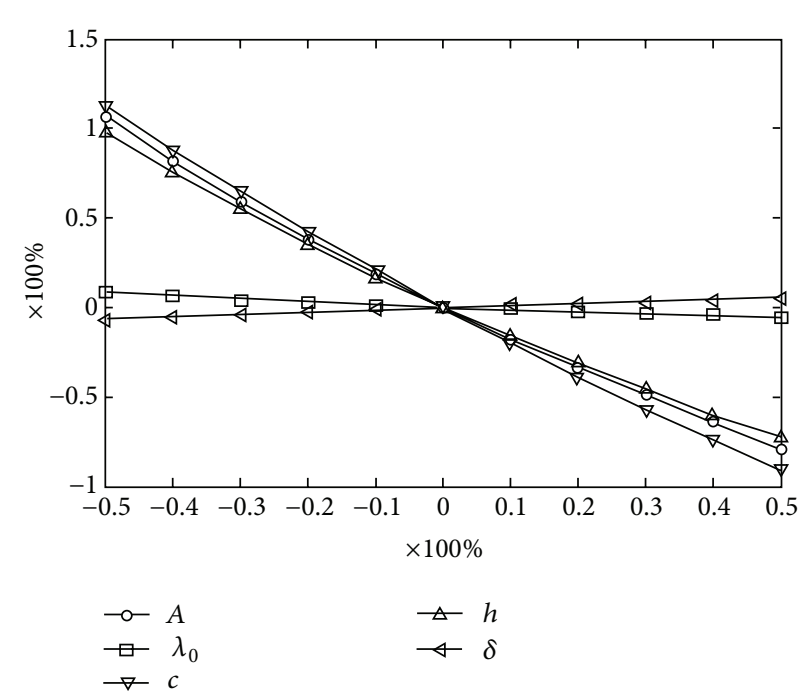

FIGURE 3: Percent changes of parameter on total profit for Example 1.

quantity is decreasing in $\delta$, the profit is increasing in $\delta$.

(3) The market price is insensitive to $\lambda_{0}$, increasing in $A$ and $c$ and decreasing in $\delta$. For the same ordering frequency, market price is increasing in $h$.
(4) The preservation cost is increasing in $A, c$, and $\lambda_{0}$, while decreasing in $h$. It means that when the ordering cost, the buying cost, and initial deterioration rate are high, the retailer will invest more to reduce the deteriorating cost. But when the holding cost rate is high, the retailer can reduce the cost by ordering more frequently instead of investing more on preservation cost.

\section{Conclusions and Future Research}

In this paper, we study a kind of deteriorating seasonal products whose deterioration rate can be controlled by investing on the preservation efforts. Then, we propose an algorithm to solve the nonlinear program problem. By analysis, we can find some properties when parameters changed. Smaller buying cost per unit, holding cost per unit time, and ordering cost can all benefit the company. Besides, when deterioration rate is relatively small or the sensitivity parameter of the investment $(\delta)$ is small, there is no need to invest the preservation technology. Also, the profit can be influenced by the constraint of the investment capital.

For future research, we can take the backlogged demand into our model. Furthermore, we can assume that the ordering lead time exists and can be controlled by extra investment. 
Also, we can extend the model to the deteriorating problems in multiechelon supply chains.

\section{Acknowledgments}

The authors thank the valuable comments of the anonymous referees for an earlier version of this paper. Their comments have significantly improved the paper. This work is supported by the National Natural Science Foundation of China (no. 71001025). Also, this research is partly supported by the Program for New Century Excellent Talents in University (no. NCET-10-0327) and the Ministry of Education of China. Grant-in-Aid for Humanity and Social Science Research (no. 11YJCZH139).

\section{References}

[1] P. M. Ghare, "A model for exponentially decaying inventory," The Journal of Industrial Engineering, vol. 5, no. 14, pp. 238-243, 1963.

[2] N. H. Shah, H. N. Soni, and K. A. Patel, "Optimization inventory and marketing policy for non-instantaneous deteriorating items with generalized type deterioration and holding cost rates," Omega, vol. 41, no. 2, pp. 421-430, 2012.

[3] S. Sana, S. K. Goyal, and K. S. Chaudhuri, "A productioninventory model for a deteriorating item with trended demand and shortages," European Journal of Operational Research, vol. 157, no. 2, pp. 357-371, 2004.

[4] A. Thangam and R. Uthayakumar, "Two-echelon trade credit financing for perishable items in a supply chain when demand depends on both selling price and credit period," Computers and Industrial Engineering, vol. 57, no. 3, pp. 773-786, 2009.

[5] Y. He and J. He, "A production model for deteriorating inventory items with production disruptions," Discrete Dynamics in Nature and Society, vol. 2010, Article ID 189017, 14 pages, 2010.

[6] Y. He, S. Y. Wang, and K. K. Lai, "An optimal productioninventory model for deteriorating items with multiple-market demand," European Journal of Operational Research, vol. 203, no. 3, pp. 593-600, 2010.

[7] Y. Liang and F. Zhou, "A two-warehouse inventory model for deteriorating items under conditionally permissible delay in payment," Applied Mathematical Modelling, vol. 35, no. 5, pp. 2221-2231, 2011.

[8] Y. He and S. Y. Wang, "Analysis of production-inventory system for deteriorating items with demand disruption," International Journal of Production Research, vol. 50, no. 16, pp. 4580-4592, 2012.

[9] K. Skouri, I. Konstantaras, S. Papachristos, and I. Ganas, "Inventory models with ramp type demand rate, partial backlogging and Weibull deterioration rate," European Journal of Operational Research, vol. 192, no. 1, pp. 79-92, 2009.

[10] J. Blackburn and G. Scudder, "Supply chain strategies for perishable products: the case of fresh produce," Production and Operations Management, vol. 18, no. 2, pp. 129-137, 2009.

[11] C. Kouki, E. Sahin, Z. Jemaï, and Y. Dallery, "Assessing the impact of perishability and the use of time temperature technologies on inventory management," International Journal of Production Economics, vol. 2010, 2010.

[12] A. Musa and B. Sani, "Inventory ordering policies of delayed deteriorating items under permissible delay in payments,"
International Journal of Production Economics, vol. 136, no. 1, pp. 75-83, 2012.

[13] P. H. Hsu, H. M. Wee, and H. M. Teng, "Preservation technology investment for deteriorating inventory," International Journal of Production Economics, vol. 124, no. 2, pp. 388-394, 2010.

[14] C. Y. Dye and T. P. Hsieh, "An optimal replenishment policy for deteriorating items with effective investment in preservation technology," European Journal of Operational Research, vol. 218, no. 1, pp. 106-112, 2012.

[15] G. C. Mahata, "An EPQ-based inventory model for exponentially deteriorating items under retailer partial trade credit policy in supply chain," Expert Systems With Applications, vol. 39, no. 3, pp. 3537-3550, 2012.

[16] M. Cheng and G. Wang, "A note on the inventory model for deteriorating items with trapezoidal type demand rate," Computers and Industrial Engineering, vol. 56, no. 4, pp. 12961300,2009

[17] C. Y. Dye, H. J. Chang, and J. T. Teng, "A deteriorating inventory model with time-varying demand and shortage-dependent partial backlogging," European Journal of Operational Research, vol. 172, no. 2, pp. 417-429, 2006.

[18] B. C. Giri, A. K. Jalan, and K. S. Chaudhuri, "Economic order quantity model with Weibull deterioration distribution, shortage and ramp type demand," International Journal of Systems Science, vol. 34, no. 4, pp. 237-243, 2003.

[19] T. H. Burwell, D. S. Dave, K. E. Fitzpatrick, and M. R. Roy, "Economic lot size model for price-dependent demand under quantity and freight discounts," International Journal of Production Economics, vol. 48, no. 2, pp. 141-155, 1997.

[20] B. R. Sarker, S. Mukherjee, and C. V. Balan, "An orderlevel lot size inventory model with inventory-level dependent demand and deterioration," International Journal of Production Economics, vol. 48, no. 3, pp. 227-236, 1997.

[21] H. L. Yang, J. T. Teng, and M. S. Chern, "An inventory model under inflation for deteriorating items with stock-dependent consumption rate and partial backlogging shortages," International Journal of Production Economics, vol. 123, no. 1, pp. 8-19, 2010.

[22] S. T. Lo, H. M. Wee, and W. C. Huang, "An integrated production-inventory model with imperfect production processes and Weibull distribution deterioration under inflation," International Journal of Production Economics, vol. 106, no. 1, pp. 248-260, 2007.

[23] H. M. Wee, J. F. Jong, and J. C. Jiang, "A note on a singlevendor and multiple-buyers production-inventory policy for a deteriorating item," European Journal of Operational Research, vol. 180, no. 3, pp. 1130-1134, 2007. 

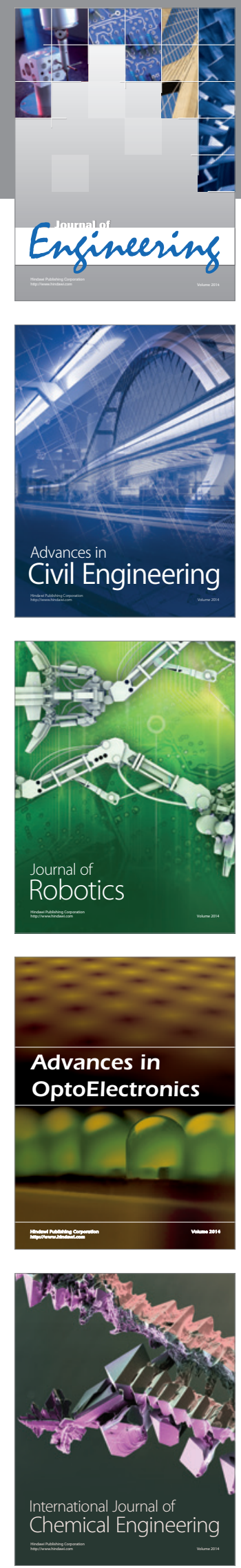

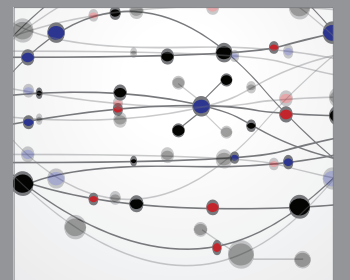

The Scientific World Journal
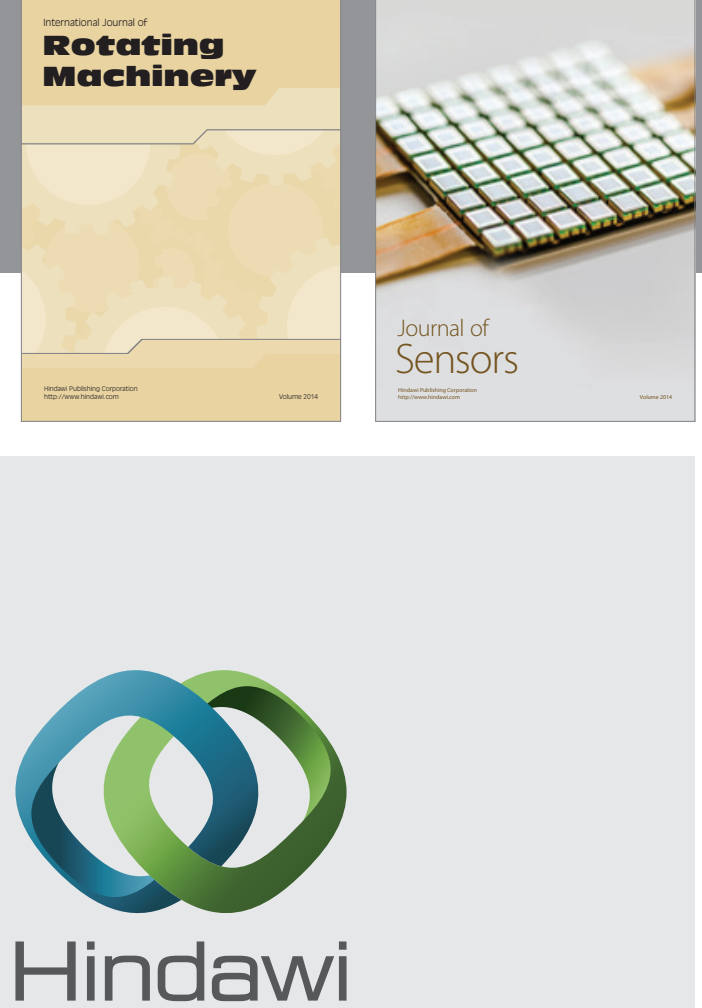

Submit your manuscripts at http://www.hindawi.com
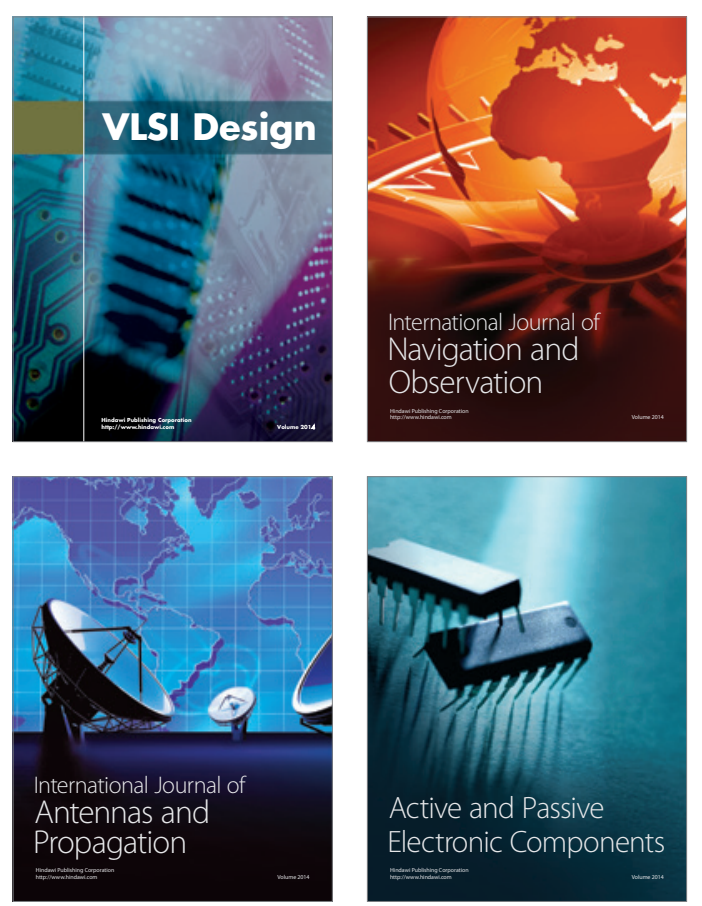
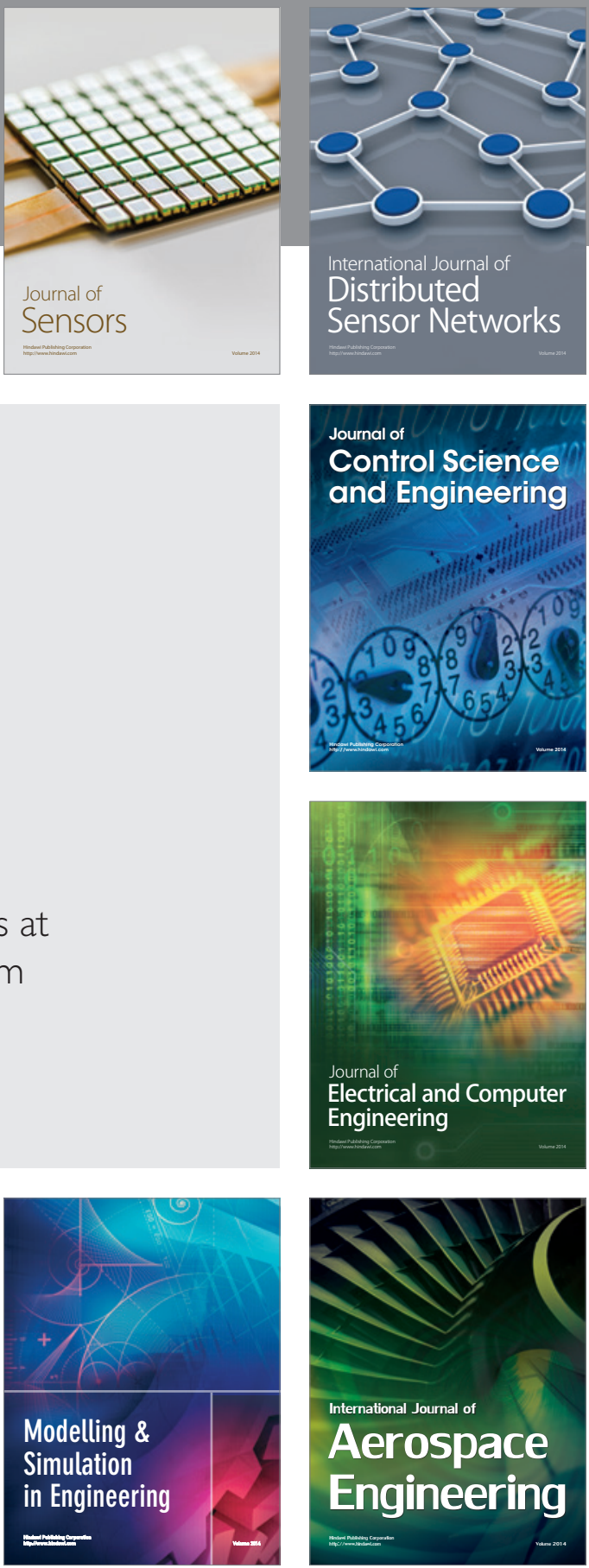

Journal of

Control Science

and Engineering
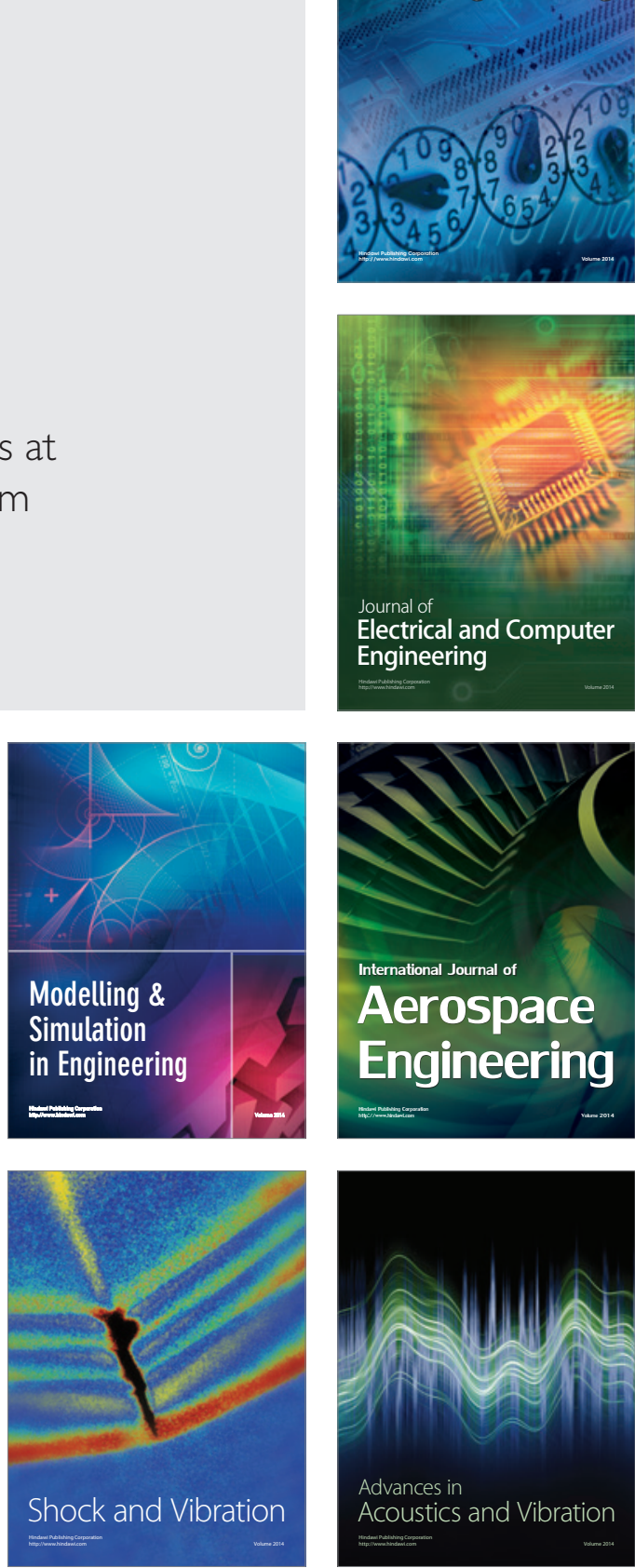